\title{
Dampak Penerapan Kultur Lokal Tri Hita Karana terhadap Orientasi Kewirausahaan dan Orientasi Pasar
}

\author{
I Gede Riana ${ }^{1}$
}

\begin{abstract}
This study aims to investigate the impact of Tri Hita Karana culture toward entrepreneurial orientation and market orientation of SMEs of silver craft in Bali. The population of this research is all small and medium size enterprises of silver craft in Bali. By using purposive random sampling, 110 small and medium size enterprises located in four regencies in Bali were selected as samples. The data collection technique was distributing questionnaires. Furthermore, to test the inter-variabels influence, inferential analysis of Structural Equation Modeling (SEM) is applied using Partial Least Square (PLS) approach. The findings of this research are Tri Hita Karana culture could improve the entrepreneurial orientation and market orientation. It was also found that the entrepreneurial orientation influence the market orientation.
\end{abstract}

Keywords: Tri Hita Karana (THK) culture, entrepreneurial orientation, market orientation.

\section{Pendahuluan}

Pentingnya keberadaan Industri Kecil Menengah (IKM) di Indonesia diperkuat oleh laporan World Bank bahwa IKM diperkirakan menyumbang sekitar 50\% lebih dari Produk Domestik Bruto (Bank Indonesia, [3]). Peran penting tersebut dapat dilihat dari berbagai aspek (Kuncoro, [17]): Pertama, IKM telah terbukti ampuh sebagai penyelamat dalam krisis ekonomi yang melanda industri. Kedua, potensinya yang besar dalam menciptakan lebih banyak kesempatan kerja. Ketiga, segmen IKM dapat ditemukan di segala sektor industri, mulai dari yang berteknologi sederhana hingga relatif canggih. Peran penting IKM juga ditegaskan Choung [6] bahwa IKM memegang peranan penting di dalam menunjang pertumbuhan ekonomi pada kebanyakan negara-negara yang ada di Asia.

Beberapa hasil kajian melaporkan bahwa IKM belum mampu memberikan kontribusi optimal karena berbagai kendala yang dihadapi, seperti; akses permodalan, akses teknologi dan informasi, akses pasar dan pemasaran, akses profesionalisme sumber daya manusia, serta akses manajemen perusahaan (Basri [4]). Penyebab dari kendala tersebut, diduga kuat karena rendahnya karakter wirausaha dan belum kokohnya peran manajerial dalam mengelola usaha pada lingkungan yang selalu berubah (Kuncoro [17]). Kewirausahaan menggambarkan suatu perilaku organisasional meliputi keberanian untuk

${ }^{1}$ Fakultas Ekonomi, Jurusan Manajemen, Universitas Udayana. Л. Jendral Sudirman, Denpasar Bali 80232.

Email: gederiana@yahoo.com.

Diterima 09 Maret 2011; revisi 30 April 2011; diterima untuk dipublikasikan 15 Mei 2011. mengambil risiko, sikap proaktif, dan inovatif (Slevin dan Covin, [7]).

Perilaku wirausaha tidak dapat dipisahkan dengan nilai-nilai budaya (kultur) masyarakat sebagai suatu kebiasaan, norma, adat istiadat yang berlaku secara turun-menurun pada suatu daerah. Mueller dan Thomas [19] mengemukakan bahwa budaya merupakan aspek penting di dalam menentukan potensi kewirausahaan, serta budaya dapat mempengaruhi perilaku pengambilan risiko (risk taking) dan tindakan proaktif (Kreiser et al. [15]). Disamping itu, karakteristik nilai-nilai budaya tertentu yang digunakan di dalam praktika organisasi dapat mempengaruhi pelaksanaan orientasi pasar perusahaan (Iweka, [12], Kuaku [16]). Selanjutnya Mueler dan Thomas [19], Baker dan Sinkula [2] memandang bahwa orientasi kewirausahaan dan orientasi pasar merupakan konstruk budaya yang tercermin di dalam budaya organisasi perusahaan.

Menurut Gima dan Anthony [9] perusahaan dengan kemampuan orientasi kewirausahaan dan orientasi pasar yang tinggi cenderung mampu berkinerja lebih baik dibandingkan dengan para pesaing dalam hal; pangsa pasar, kecepatan di dalam memasuki pasar, dan tingkat kualitas produk. Dijelaskan pula bahwa orientasi kewirausahaan dan orientasi pasar merupakan konsep yang saling berhubungan yang mampu membawa perusahaan menuju kinerja unggul (Becherer dan Maurer [5]; Vitale et al. [25]; Todorovic dan Ma [24]).

Terkait dengan konsep orientasi kewirausahaan dan orientasi pasar, Todorovic dan Ma [24] mengkaji pengaruh orientasi pasar dan orientasi kewirausahaan terhadap kinerja usaha pada perspektif 
lintas budaya. Secara spesifik dijelaskan bahwa selama ini, kajian tentang hubungan kedua konsep tersebut hanya dilakukan pada negara-negara barat. Kajian tersebut cenderung fokus pada pengaruh kekuatan lingkungan organisasi sehingga mengabaikan dampak budaya nasional terhadap orientasi pasar dan orientasi kewirausahaan. Hasil kajiannya menemukan bahwa nilai-nilai budaya nasional berdampak signifikan terhadap orientasi kewirausahaan dan orientasi pasar. Selanjutnya Sinkula dan Baker [2] memandang orientasi kewirausahaan dan orientasi pasar adalah dua aspek yang saling berhubungan namun memberikan pengaruh yang berbeda. Hal ini karena orientasi kewirausahaan merefleksikan pertumbuhan perusahaan yang dipicu oleh identifikasi dan eksploitasi peluang pasar yang belum dimanfaatkan, sebaliknya orientasi pasar merefleksikan perencanaan pasar stratejik perusahaan yang dipicu oleh pelaksanaan intelejensi pelanggan dan pesaing.

Berdasarkan fenomena di atas, maka permasalahan yang akan dikaji adalah apakah nilai-nilai kultur THK berpengaruh terhadap orientasi kewirausahaan dan orientasi pasar. Untuk menjawab permasalahan penelitian tersebut akan dilakukan kajian terhadap Industri Kecil Menengah (IKM) kerajinan perak, yang didasarkan atas pertimbangan bahwa industri ini merupakan IKM unggulan dengan nilai ekspor terbesar di Provinsi Bali.

\section{Metode Penelitian}

Penelitian ini mengkaji dampak penerapan nilai kultur THK terhadap orientasi kewirausahaan dan orientasi pasar pada IKM kerajinan perak di Bali. Berdasarkan karakteristik masalah yang diteliti, penelitian ini diklasifikasikan ke dalam penelitian kausal, yaitu penelitian dengan karakteristik masalah berupa hubungan sebab akibat antara dua variabel atau lebih. Peneliti melakukan pengamatan terhadap konsekuen-konsekuen yang timbul dan menelusuri kembali fakta secara masuk akal sebagai faktor-faktor penyebabnya. Sebaliknya, penelitian ini menggunakan pendekatan kuantitatif (positivism), yaitu pendekatan penelitian yang bekerja dengan angka, datanya berwujud bilangan, dianalisis dengan menggunakan statistik untuk menjawab pertanyaan dan menguji hipotesis penelitian yang sifatnya spesifik. Selanjutnya, hasil analisis digunakan untuk melakukan prediksi bahwa suatu variabel tertentu mempengaruhi variabel yang lain (Creswell, [8]).

Populasi penelitian adalah seluruh Industri Kecil Menengah (IKM) kerajinan perak di Provinsi Bali. Sampel ditentukan dengan menggunakan purposive random sampling dengan kuesioner sebagai instru- ment pengumpulan data. Dari 145 kuesioner yang disebarkan, dipilih 110 kuesioner yang telah diisi secara lengkap sekaligus merupakan data yang akan dianalisis. Data yang telah terkumpul dianalisis dengan menggunakan Structural Equation Modeling (SEM) menggunakan pendekatan variance based atau component based yaitu analisis Partial Least Square (PLS). Untuk menjawab permasalahan penelitian, dikembangkan hipotesis yang dibangun dari kerangka teori dan beberapa hasil penelitian terdahulu.

\section{Dampak Kultur THK terhadap Orientasi Kewirausahaan dan Orientasi Pasar}

Budaya merupakan suatu pengetahuan dimana masyarakat menggunakan pengalamannya untuk menghasilkan suatu sikap diri dan perilaku sosial (Hodgetts dan Luthan [10]). Budaya merupakan sekumpulan pengetahuan, kepercayaan, seni, moral, hukum, adat dan kebiasaan yang diperoleh sebagai anggota sebuah perkumpulan atau komunitas tertentu (Susanto et al. [23]). Kumpulan budaya-budaya inilah nantinya membentuk budaya nasional yang membedakan mereka dalam menetapkan tujuan. Budaya nasional merupakan suatu pola pemikiran, perasaan dan tindakan satu kelompok sosial, yang membedakannya dengan kelompok sosial lain (Hofstede [11]).

Dunia tradisi Bali yang berjiwa Hindu dengan elemen pemujaan alam dan para leluhur adalah hasil evolusi dan akulturasi dari beberapa budaya yang datang ke pulau Bali. Sistem dan tatanan kehidupan seperti desa adat dengan sistem banjar yang direkat oleh konsep tiga pura yang disebut Kahyangan Tiga (Puseh, Desa, Dalem) dan pura keluarga (Merajan) serta organisasi pertanian bernama subak diperkirakan telah mulai diterapkan di Bali sejak awal abad ke 11, dan hingga kini masih tetap kuat keberadaannya. Beberapa konsep tersebut merupakan awal munculnya Tri Hita Karana (THK). Konsep THK merupakan konsep nilai kultur lokal yang telah tumbuh, berkembang dalam tradisi masyarakat Bali, dan bahkan saat ini telah menjadi landasan falsafah bisnis, filosofi pengembangan pariwisata, pengaturan tata ruang, dan rencana stratejik pembangunan daerah.

Filosofi hidup masyarakat Hindu di Bali menuju jagadita dan moksa telah berkembang menjadi tujuan hidup masyarakat yaitu catur purusa artha, artinya empat tujuan hidup yang terdiri dari dharma, artha, kama, dan moksa. Konsep ini mengandung makna bagaimana mencari keharmonisan dengan tidak semata-mata mencari materi, namun bagaimana tujuan hidup untuk mendapatkan kebahagian yang kekal. Tujuan hidup tersebut 
dapat diwujudkan dengan kebajikan sebagai dasar kehidupan (dharma), supaya memperoleh harta benda sebagai sarana dan penunjang kehidupan (artha), sehingga dapat dinikmati untuk kesejahteraan (kama), serta untuk mewujudkan kebahagiaan yang sejati $(m o k s a)$. Dalam pelaksanaannya, catur purusa artha dilhami oleh konsep catur warna yaitu konsep professional yang didasarkan atas bidang-bidang yang akan dikerjakan (seperti entrepreneur, kesenian, sastra, dan lainnya) yang disesuaikan dengan tingkatan hidup seseorang (catur asrama). Ketiga konsep catur inilah akhirnya terelaborasi yang mendasari way of life masyarakat Hindu di Bali dalam melaksanakan aktivitas keseharian.

Sebagian besar, atau bahkan dapat dikatakan hampir seluruh masyarakat Bali yang beragama Hindu tergerak di dalam pemahaman terhadap agama melalui pendekatan yadnya. Filosofi yadnya, menyangkut tentang pengorbanan yang dilakukan oleh umat Hindu di Bali, baik pengorbanan terhadap Tuhan (dewa yadnya), kepada guru atau pendeta (rsi yadnya), sesama manusia (manusa yadnya), para leluhur (pitra yadnya), dan lingkungan serta makhluk lain (butha yadnya) yang disebut dengan panca yadnya. Bagi masyarakat Hindu Bali, melakukan panca yadnya merupakan cerminan dalam rangka melaksanakan konsep THK. Konsep THK merupakan konsep harmonisasi hubungan yang selalu dijaga masyarakat Hindu Bali meliputi: parahyangan (hubungan manusia dengan Tuhan), pawongan (hubungan antar-manusia), dan palemahan (hubungan manusia dengan lingkungan) yang bersumber dari kitab suci agama Hindu Baghawad gita. Oleh karena itu, konsep THK yang berkembang di Bali, merupakan konsep budaya yang berakar dari ajaran agama.

Pelaksanaan konsep THK dalam menjaga harmonisasi, baik secara vertikal (Tuhan) maupun horizontal (manusia dan lingkungan) menuntut masyarakat Hindu Bali untuk selalu melakukan yadnya yang sudah tentu akan memerlukan sarana penunjang dalam bentuk artha. Di samping itu, adanya pola konsumsi untuk ritual yang cukup tinggi atau kalau boleh dikatakan sangat tinggi, telah mendorong masyarakat Hindu di Bali untuk bekerja keras agar dapat memenuhi kebutuhan hidupnya. Penelitian Sukarsa dalam Ramantha [22] menunjukkan bahwa sekitar 32\% dari pendapatan orang Hindu di Bali digunakan untuk konsumsi ritual agama dalam bentuk yadnya. Pengeluaran tersebut merupakan salah satu cermin pemahaman dan pelaksanaan terhadap nilai-nilai agama (Ramantha, [22]).

Konsep artha (dalam catur purusa artha) dan panca yadnya inilah akhirnya mendorong masyarakat
Hindu di Bali untuk bekerja keras agar memperoleh pendapatan untuk memenuhi segala kebutuhannya, termasuk keperluan ritual dalam bentuk yadnya. Namun demikian, dalam pelaksanakannya konsep artha tidak dapat terlepas dari konsep catur purusa artha lainnya, dimana dalam mencari artha (kekayaan) haruslah berpedoman pada konsep dharma, kama, dan moksa yang dalam penerapannya masih sering saling dipertukarkan.

THK merupakan sebuah filosofi sekaligus telah menjadi way of life masyarakat Bali dalam segala aspek kehidupan. THK mengandung elemen parahyangan (hubungan harmonis antara manusia dengan Tuhan), pawongan (hubungan harmonis antarmanusia), palemahan (hubungan harmonis antara manusia dengan lingkungan), yang pada dasarnya analog dengan sistem kebudayaan (Windia dan Ratna, [27]). Konsep budaya THK merupakan konsep yang mengedepankan prinsip-prinsip kebersamaan, keselarasan, dan keseimbangan antara tujuan ekonomi, pelestarian lingkungan dan budaya, serta estetika dan spiritual. Sehubungan dengan itu, para pelaku bisnis beserta seluruh komponen masyarakat Bali diwajibkan mengimplementasikan budaya THK dalam segala aspek kehidupan. Demikian pula dalam pelaksanakan aktivitas bisnis seharusnya mempertimbangkan keseimbangan antara pemenuhan kebutuhan duniawi dan kebutuhan yang bersifat surgawi (religius).

Windia [26] mengungkapkan bahwa apabila prinsip parahyangan dikaitkan dengan bisnis, harus disadari bahwa aktivitas manusia yang berbisnis itu adalah persembahan kepada Tuhan. Kegiatan bisnis tidak hanya untuk satu tujuan, yakni menikmati keuntungan maksimal, namun harus ada kesadaran dari kalangan bisnis bahwa kegiatan yang dilakukan pada hakikatnya dikontrol oleh Tuhan. Demikian pula, apabila prinsip pawongan dikaitkan dengan kegiatan bisnis maka para pelaku bisnis pada hakekatnya adalah sosok manusia sebagai makhluk Tuhan yang tidak berbeda dengan sesama manusia lainnya. Pelaku bisnis haruslah menjaga harmonisasi dengan sesama secara internal di dalam perusahaan maupun secara eksternal dengan lingkungan agar tidak terjadi konflik dengan para stakeholders.

Dalam palemahan pelaku bisnis diharapkan mampu menjaga harmonisasi hubungan dengan lingkungan. Apabila terjadi disharmoni, misalnya dengan cara mengeksploitasi lingkungan secara berlebihan, maka pada saatnya pasti akan membahayakan kelangsungan kegiatan bisnis (Windia dan Ratna, [27]). Terkait dengan palemahan, Koentjaraningrat, [14] menekankan bahwa manusia bisa bertindak dengan menguasai lingkungan, 
tunduk kepada lingkungan, atau bertindak serasi dan harmonis dengan lingkungan. Atas dasar alasan tersebut, para pelaku bisnis di Bali berkewajiban mengedepankan prinsip-prinsip keseimbangan berdasarkan konsep THK. Hal ini dimaksudkan agar pelaksanaan aktivitas bisnis sesuai dengan tujuan dan kaidah nilai-nilai budaya dan agama sehingga segala hasil yang didapat (artha) dilandasi oleh nilai-nilai dharma.

Beberapa peneliti seperti Mueller dan Thomas [19], Kreiser et al. [15] menyatakan bahwa atribut-atribut kultural dapat memiliki dampak kuat pada pembentukan dan tingkah laku kewirausahaan. Knight dalam Anisah [1] mengemukakan bahwa hanya negara-negara dengan tendensi budaya tertentu yang akan menghasilkan orientasi kewirausahaan yang kuat dan karenanya akan mengalami lebih banyak kegiatan kewirausahaan dan daya saing global. Selanjutnya dijelaskan bahwa perbedaan pandangan dan asumsi yang tertanam di dalam suatu budaya tidak hanya tercermin dalam sikap dan kepercayaan manajerial, melainkan juga dalam perilaku-perilaku dan kegiatan-kegiatan yang dilakukan. Oleh karena itu, budaya bertanggung jawab dalam mendorong seseorang untuk terikat dalam perilaku yang tidak lazim seperti di negara-negara lain (Mueller dan Thomas, [19]). Dengan demikian, jika budaya mempengaruhi orientasi strategik yang ditampilkan oleh organisasi, maka kemungkinan budaya akan menentukan tingkat orientasi kewirausahaan suatu perusahaan secara keseluruhan.

Orientasi kewirausahaan sering kali dihubungkan dengan orientasi pasar, karena merupakan dua orientasi stratejik yang mampu membawa perusahaan menuju kinerja unggul (Baker dan Sinkula, [2]). Dijelaskan pula bahwa orientasi kewirausahaan dan orientasi pasar adalah dua konstruk yang saling terkait (Vitale, et al, [25]: Lim, [18]) dan merupakan konstruk budaya (Baker dan Sinkula, [2]). Oleh karena itu, nilai-nilai budaya akan cenderung mempengaruhi interaksi antara orientasi kewirausahaan dan orientasi pasar (Tudorovic \& Ma, [23]).

Berdasarkan uraian di atas diajukan hipotesis penelitian sebagai berikut.

Hipotesa 1 : Nilai-nilai kultur THK berpengaruh signifikan terhadap orientasi kewirausahaan.

Hipotesis 2: Nilai-nilai kultur $T H K$ berpengaruh signifikan terhadap orientasi pasar.

Hipotesis 3 : Orientasi kewirausahaan berpengaruh signifikan terhadap orientasi pasar.

Dari rumusan hipotesis di atas dapat dibangun kerangka konseptual penelitian sebagai berikut (Gambar 1)

\section{Hasil dan Pembahasan}

\section{Uji Validitas dan Reliabilitas}

Sebelum melakukan pembahasan dipastikan terlebih dahulu bahwa instrumen yang digunakan di dalam penelitian semuanya valid dan reliabel. Hasil uji reliabilitas menunjukkan nilai Alpha Cronbach berkisar antara 0,6708 - 0,8107 $(>0,6)$. Convergent validity menunjukkan korelasi antara skor indikator refleksif dengan Loading faktor skor variabel laten antara 0,652 - 0,890 $(>0,5)$. Sedangkan Discriminant validity, menunjukkan nilai square root of average variance extracted (AVE) setiap konstruk, dengan korelasi antar konstruk lainnya dalam model dengan nilai 0,538 - 0,767 $(>0,5)$. Demikian pula Composite reliability, menunjukkan bahwa indikator blok yang mengukur konsistensi internal dari indikator pembentuk konstruk dengan nilai 0,775 $0,908(>0,7)$. Dengan demikian semua konstruk dinyatakan valid dan reliable.

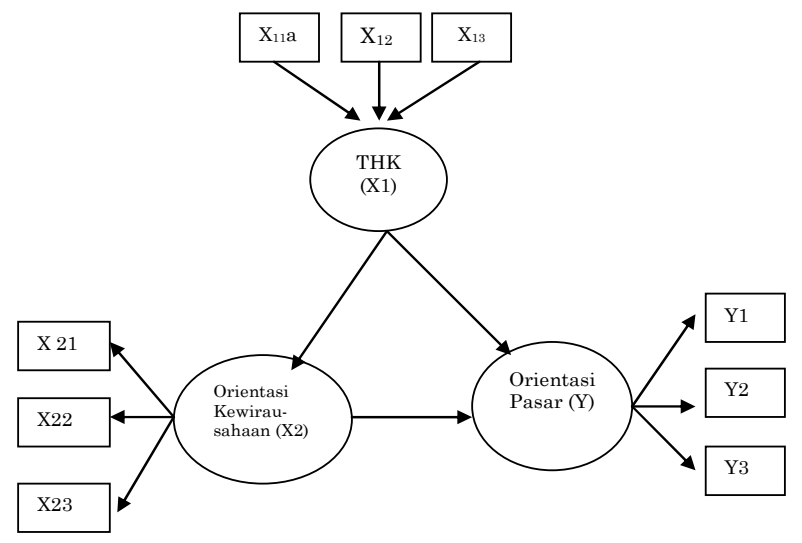

Gambar 1. Kerangka konseptual penelitian

Tabel 1. Indikator variabel penelitian

\begin{tabular}{clrl}
\hline \multicolumn{2}{l}{ Indikator } & Keterangan & \multicolumn{2}{l}{ Indikator } & Keterangan \\
\hline X11 & Parahyangan & Y1 & $\begin{array}{l}\text { Pengetahuan } \\
\text { tentang pasar }\end{array}$ \\
X12 & Pawongan & Y2 & $\begin{array}{l}\text { Penyebarluasan } \\
\text { informasi pasar }\end{array}$ \\
X13 & Palemahan & Y3 & $\begin{array}{l}\text { Kontribusi } \\
\text { aktivitas pema- }\end{array}$ \\
& & & saran \\
X21 & Inovatif & & \\
X22 & Proaktif & & \\
X23 & Risiko & & \\
\hline
\end{tabular}

Tabel 2. Nilai R2 variabel endogen

\begin{tabular}{lc}
\hline \multicolumn{1}{c}{ Variabel Endogen } & $R$-square \\
\hline Orientasi kewirausahaan (X2) & 0,375 \\
Orientasi pasar (Y) & 0,574 \\
\hline
\end{tabular}

Nilai predictive-relevance diperoleh dengan rumus:

$\mathrm{Q}^{2}=1-\left(1-\mathrm{R}_{1}^{2}\right)\left(1-\mathrm{R}_{2}{ }^{2}\right)$

$\mathrm{Q}^{2}=1-(1-0,375)(1-0,574)=0,7337$ 
Hasil perhitungan di atas memperlihatkan nilai $Q^{2}$ sebesar 0,7337 (>0), maknanya adalah 73,37\% variasi pada variabel orientasi pasar (dependent variabel) dijelaskan oleh variabel-variabel yang digunakan.

\section{Hasil Uji Faktor Konfirmatori}

Hasil analisis faktor konfirmatori menunjukkan bahwa pawongan merupakan determinan utama dari kultur THK (Gambar 2.) pada IKM kerajinan perak di Bali. Sehingga secara konseptual pawongan merupakan faktor penting sebagai wujud penerapan nilai-nilai kultur THK. Pawongan merefleksikan antar sesama manusia wajib menjaga hubungan yang harmonis atas dasar prinsip kebersamaan, baik antar karyawan, karyawan dengan atasan maupun dengan seluruh stakeholder. Menurut Pitana [21] manusia memegang peran strategis karena disamping sebagai objek, manusia juga bertindak sebagai subjek. Oleh karena itu, menjaga harmonisasi antar-manusia (stakeholders) mutlak diperlukan dalam menjalankan aktivitas bisnis.

Inovatif merupakan determinan utama orientasi kewirausahaan (loading faktor 0,838 ) diikuti dengan risiko $(0,698)$ dan proaktif $(0,652)$. Hal ini berarti bahwa sikap inovatif seperti menemukan target usaha baru, menciptakan produk baru, dan menciptakan nilai bagi pelanggan dapat membantu perusahaan dalam memenangkan kompetisi. Disamping itu, keberanian mengambil risiko, membina kemitraan dengan partner, menetapkan harga secara proaktif, kekuatan penjualan dan periklanan, dan selalu berkeinginan untuk mengalahkan pesaing merupakan faktor penting dalam menghadapi pesaing.
Nilai loading faktor orientasi pasar menunjukkan pengetahuan tentang pasar sebagai determinan utama orientasi pasar. Faktor penting lain dari orientasi pasar adalah penyebarluasan informasi pasar dan kontribusi aktivitas pemasaran. Pengetahuan tentang pasar meliputi kemampuan untuk mengetahui kebutuhan pelanggan, memperhatikan proses keputusan dari para pelanggan, mampu mengetahui strategi-strategi para pesaing, dan memperhatikan kelemahan para pesaing.

\section{Hasil Pengujian Hipotesis}

Hasil uji hipotesis menunjukkan bahwa tiga hipotesis yang dikemukakan, semuanya dinyatakan signifikan, dan selanjutnya akan diuraikan berikut.

Hasil analisis menunjukkan bahwa penerapan nilainilai kultur lokal THK berpengaruh signifikan terhadap orientasi kewirausahaan. Maknanya adalah, penerapan nilai-nilai kultur lokal THK memberikan kontribusi penting dalam meningkatkan orientasi kewirausahaan. Hal ini mengindikasikan bahwa nilai-nilai harmonisasi yang terkandung dalam kultur THK terbukti mampu meningkatkan kemampuan orientasi kewirausahaan. Semakin baik harmonisasi hubungan dengan Tuhan (parahyangan), antarsesama (pawongan), dan dengan lingkungan (palemahan), maka akan semakin tinggi kemampuan orientasi kewirausahaan. Hasil penelitian ini telah mengkonfirmasi penelitian Muller dan Thomas [19] bahwa budaya dapat menentukan potensi kewirausahaan. Demikian pula temuan Kreiser et.al [15] bahwa budaya mempengaruhi suatu organisasi di dalam perilaku pengambilan risiko (risk taking) dan tindakan proaktif (proactive). Hasil uji hipotesis (Gambar 2) menunjukkan bahwa

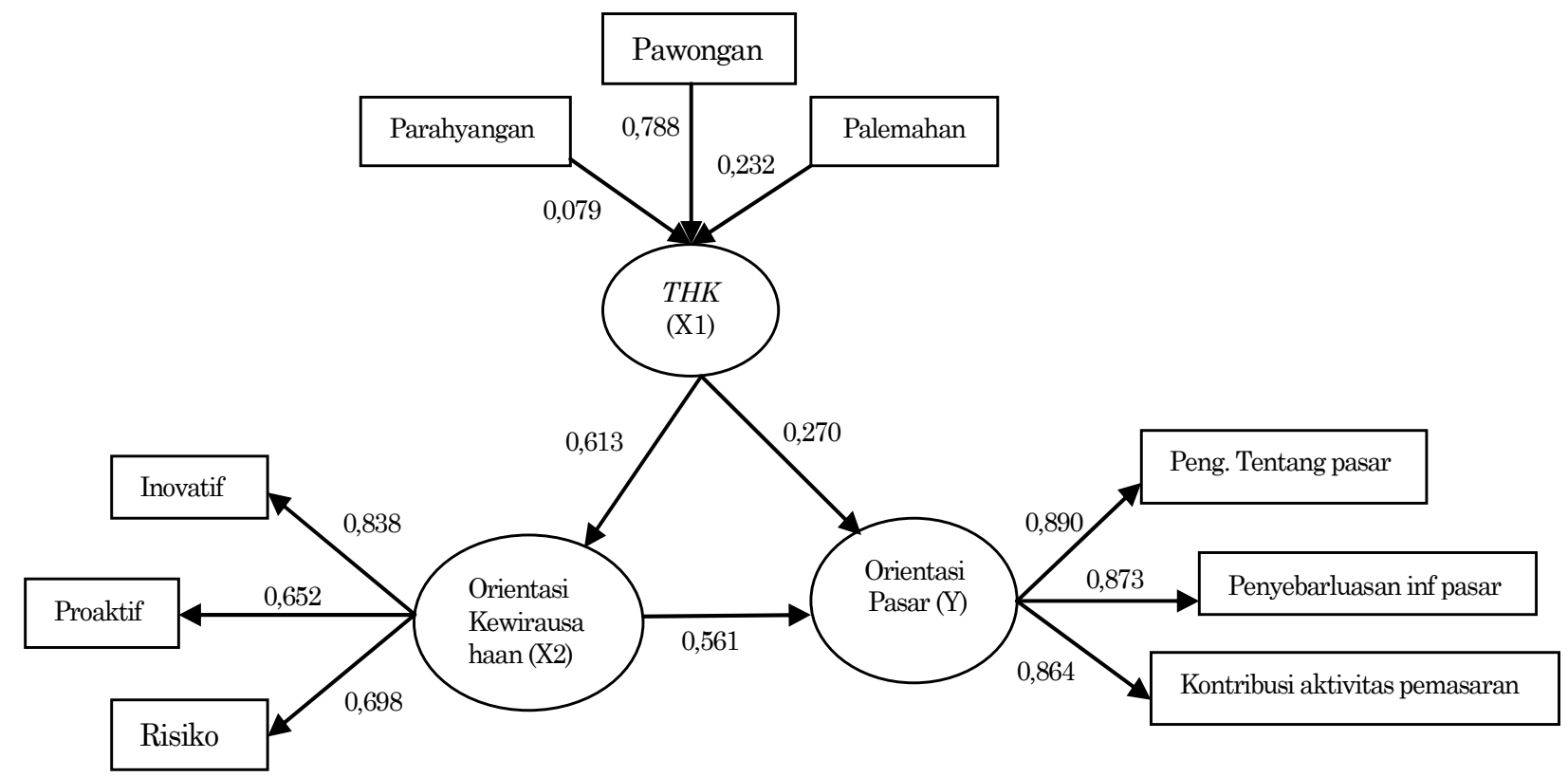

Gambar 2. Diagram path analisis PLS 
nilai-nilai harmonisasi yang terkandung di dalam kultur THK berpengaruh signifikan terhadap orientasi pasar. Dengan demikian, penerapan nilai-nilai kultur THK yang semakin baik telah terbukti mampu meningkatkan pelaksanaan orientasi pasar. Hal ini terbukti dari pengaruh signifikan antara nilainilai kultur THK terhadap orientasi pasar. Temuan ini mengkonfirmasi hasil kajian Kuaku [16] bahwa nilai-nilai budaya yang digunakan didalam praktika organisasi memiliki pengaruh positif signifikan dengan orientasi pasar. Temuan ini juga mengkonfirmasi kajian Iweka [12] tentang pengaruh budaya terhadap orientasi pasar pada usaha kecil bahwa terdapat pengaruh positif signifikan antara nilai budaya yang digunakan dalam praktika organisasi dengan orientasi pasar.

Orientasi kewirausahaan berpengaruh signifikan terhadap orientasi pasar. Maknanya bahwa semakin tinggi orientasi kewirausaan maka semakin tinggi tingkat orientasi pasar. Oleh karena itu, kemampuan untuk melakukan inovasi, selalu proaktif, dan keberanian untuk mengambil risiko berperan penting dalam menunjang pelaksanaan orientasi pasar. Temuan ini mengkonfirmasi kajian dari Becherer dan Maurer [5] bahwa orientasi kewirausahaan saling berhubungan langsung dengan orientasi pasar. Demikian pula mengkonfirmasi hasil beberapa kajian seperti; Jaworski dan Kohli [13], Narver dan Slater [20] dan Vitale et al., [25] bahwa terdapat pengaruh signifikan antara orientasi kewirausahaan dan orientasi pasar. Selanjutnya Baker \& Sinkula [2] menjelaskan bahwa orientasi kewirausahaan lebih merupakan anteseden dari orientasi pasar, sedangkan Tudorovic dan Ma, [24] mengemukakan bahwa orientasi kewirausahaan dan orientasi pasar merupakan dua orientasi stratejik yang saling berinteraksi.

\section{Simpulan}

Berdasarkan penelitian terhadap beberapa Industri Kecil Menengah (IKM) kerajinan perak di Bali didapatkan hasil bahwa nilai-nilai harmonisasi yang terkandung didalam kultur THK terbukti mempengaruhi secara signifikan kemampuan orientasi kewirausahaan. Semakin baik penerapan nilai-nilai kultur THK maka semakin tinggi kemampuan orientasi kewirausahaan. Demikian pula nilai-nilai kultur THK terbukti secara signifikan berpengaruh terhadap orientasi pasar. Sedangkan, kemampuan orientasi kewirausahaan yang semakin baik terbukti mampu meningkatkan pelaksanaan orientasi pasar pada IKM kerajinan perak.

Penelitian ini juga telah membuktikan bahwa aspek pawongan (harmonisasi hubungan antar-manusia) merupakan aspek penting didalam kultur lokal
THK, sikap inovatif merupakan aspek penting di dalam orientasi kewirausahaan, selanjutnya pengetahuan tentang pasar merupakan aspek penting dalam pelaksanaan orientasi pasar. Dengan demikian, penelitian ini telah membuktikan bahwa nilainilai kultur lokal THK memberikan kontribusi penting di dalam mempengaruhi kemampuan orientasi kewirausahaan dan orientasi pasar.

\section{Daftar Pustaka}

1. Anisah, A. U., Kewirausahaan Islami berbasis Budaya Lokal. Prosiding Seminar Kewirausahaan I, Pengembangan Entrepreneur Berdaya Saing Internasional Melalui Pemanfaatan Budaya Lokal, 20 januari 2010 Malang. pp. 353-364.

2. Baker, W. E., and Sinkula, J. M., The Complementary Effect Market Orientation and Entrepreneurial Orientation on Profitability in Small Business. Journal of Small Business Management, 47 (4), 2009, pp. 443-464.

3. Bank Indonesia, Hasil Penelitian Profil UMKM di Indonesia. Biro Kredit Bank Indonesia, Jakarta, 2005.

4. Basri, F. H., Dinamika UKM diantara Gemuruh Retorika Politik dan Mitos. Seminar Pembangunan Hukum Nasional VIII, Tema Penegakan Hukum dalam Era Pembangunan Berkelanjutan. Badan Pembinanaan Hukum Nasional Dep. Kehakiman dan Hak Asasi Manusia RI Denpasar, 14-18 Juli 2003.

5. Becherer, R. C., and Maurer, The Moderating Effect of Environmental Variable on the Entrepreneurial and Marketing Orientation of Entrepreneur Led Firm. Entrepreneurship Theory and Practice, 22(1), 1997, pp. 47-58.

6. Choung, S., A Taxanomy of operation Strategies of High Performing Small and Medium Enterprises in Singapore. International Journal of Operations and Production Management, 24, 2004, pp. 321-335.

7. Covin, J. G., and Slevin, D. P., A Conceptual Model of Entrepreneurship as Firm Behavior. Entrepreneurship Theory and Practice, 16, 1991, pp. 7-25.

8. Creswell, W. J., Research Design Qualitative, Quantitative, and Mixed Methods. Sage Publication, India, 2002.

9. Gima, K., and Anthony, K., An Empirical Investigation of the Effect of Market Orientation and Entrepreneurship Orientation Allignment on Product Inovation. Organization Sciene, 12(1), 2001, pp. 54-74.

10. Hotgetts, E. M., and Luthans, F., International Management, 2nd edition, New York, Mc. Graw Hill, Inc., 1994.

11. Hofstede, G., Cultures and Organizations, McGraw-Hill, New York., 1991.

12. Iweka, N. H. Organizational Size and Culture: 
the Effect on the Implementation of the Marketing Concept Dissertation. Presented in Partial Fulfillment of the Requirements for the Degree Doctor of Philosophy, Capella University August 2007.

13. Jaworski, B., and Kohli, A. Z., Market Orientation: Antecedents and Consequences. Journal of Marketing, 57, 1997, pp. 53 -70.

14. Koentjaraningrat. Kebudayaan Mentalitas dan Pembangunan. Gramedia Pustaka Utama, Jakarta, 2005

15. Kuaku, A. and Blankson, C. Business Strategy, Organization Culture and Market Orientation. Thunderbird International Business Review. 40(3), May/Jun 1998, pp. 235, 1998.

16. Kuncoro, M., Strategi Pemberdayaan Usaha Kecil di Indonesia. Disajikan dalam Stadium Jenderal di STIE Kerja Sama, Yogyakarta, 18 Nopember 2000.

17. Lim, Seongbae, Entrepreneurial Orientation and the Performance of Service Business, St. Mary's University. One Camino Santa Maria, San Antonio, TX 78228, 2002.

18. Mueler, S. L., and Thomas, A. S., Culture and Entrepreneurial Potential: A Nine Country Study of Locus Control and Innovativeness. Journal of Business Venturing, 16 (1), 2001, pp. 51-75

19. Narver, J. C., and Slater, S. F., The Effect of Market Orientation on Busness Profitability. Journal of Marketing, October, 1990, pp. 20-35.

20. Kreiser, P. D., Marino, and Weaver, K. M.,
Assessing the Psychometric Properties of Entrepreneurial Orientation Scale: A Multi Country Analysis. Journal of Entrepreneurship Theory and Practise, 26, 2002, pp. 71-103.

21. Pitana, I G., Wahana Pelestarian Kebudayaan dan Dinamika Masyarakat Bali. Dalam Pidato Ilmiah Pengukuhan Guru Besar, Universitas Udayana, Denpasar, 2002.

22. Ramantha, W., Kewirausahaan Hindu. Prosiding Seminar Kewirausahaan I, Pengembangan Entrepreneur Berdaya Saing Internasional Melalui Pemanfaatan Budaya Lokal. 20 januari 2010 Malang. pp. 245-258

23. Susanto, A. B., Sujanto, and Wijanarko, H., Coorporate Culture and Organization Culture, A Strategic Management Approach. The Jakarta Consulting Group, Jakarta, 2008.

24. Todorovic, Z. W., and J. Ma., Entrepreneurial and Market Orientation Relationship to Performance. The Multicultural Perspektif. Journal of Enterprising Communities, 2(1), 2008, pp. 21-36.

25. Vitale, R., Giglierano, J., and Miles, M., Entrepreneurial Orientation, Market Orientation and Performance in Established and Start up Firms. 2003, Working Paper.

26. Windia, W., Analisis Bisnis yang Berlandaskan Tri Hita Karana. Wahana Edisi 55 tahun XXII. Agustus, Bukit Jimbaran: IKAYANA, 2005.

27. Windia, W., dan Ratna, K. D., Analisis Bisnis yang Berlandaskan Tri Hita Karana. Penerbit Universitas Udayana, Denpasar, 2007. 